\title{
НАКОПЛЕНИЕ РТУТИ В ТКАНЯХ РЫБ ВОДОЕМОВ МУРМАНСКОЙ ОБЛАСТИ И ПРИГРАНИЧНЫХ РАЙОНОВ НОРВЕГИИ И ФИНЛЯНДИИ
}

\section{Терентьев П.М., Кашулин Н.А., Даувальтер В.А., Королева И.М.}

Институт проблем промышиленной экологии Севера КНЦ РАH, Anamumbl, p_terentjev@inep.ksc.ru

Известно, что процессы аккумуляции ртути в природных средах и живых организмах Арктики, помимо влияния локальных источников промышленного загрязнения, тесно связаны с ее распространением за счет процессов глобально атмосферного переноса $[5,8,14]$. Оценка токсического влияния ртути на биологические организмы является актуальной научной задачей. При этом, среди гидробионтов, ответные реакции рыб на ртутное загрязнение, как представителей позвоночных животных, наиболее часто используются для оценки потенциального вреда здоровью человека, степени токсичности среды $[2,3,4,6,7,9,12,13]$. Целью данной работы являлось выявление особенностей накопления ртути в тканях рыб разнотипных водоемов Мурманской области, а также сопредельных территорий Северной Финляндии и Норвегии, и разработка единых подходов к нормированию содержания ртути в тканях рыб стран Евро-Арктического региона.

Основной проблемой при оценке закономерностей накопления ртути в компонентах природных сред и, в частности, в рыбе для России и сопредельных европейских стран является отсутствие единых норм содержания ртутьсодержащих веществ. Учитывая высокую токсичность соединений ртути, в России до настоящего момента действуют достаточно завышенные нормативы ПДК. Так, допустимое содержание ртути в мышечной ткани рыб достигает 0.5 мкг/г сырого веса (что соответствует содержанию 2.3 мкг/г сухого веса), в то время как аналогичные показатели ВОЗ для отдельных групп населения не должны были превышать 0.2 мкг/г сырого веса [15]. Для ряда стран северной Европы, в частности Финляндии, с 2000 г установлены величины концентраций ртути с учетом ряда природных показателей водоемов (фоновых величин) в диапазоне 0.20-0.25 мкг/г сырого веса (что в среднем соответствует 1.1 мкг/Г сухого веса).

Изучение особенностей накопления ртути в организмах различных видов рыб более чем 50 водоемов исследованного региона показал, что значительные содержания металла, превышающие величины 0.5 мкг/г сырого веса, как правило, характерны для рыб малых озер Норвегии, Финляндии и России. Наиболее высокие концентрации металла обнаружены в рыбах озер, удаленных от крупных промышленных предприятий региона. Причем для окуня и щуки максимальные величины накопления были зарегистрированы именно в мышечной ткани. Анализ многолетних материалов показал, что в накоплении ртути в организмах рыб прослеживается тенденция к увеличению за последнее десятилетие (рис. 1). Аналогичные закономерности были отмечены и для рыб водоемов северной Финляндии и Норвегии [11]. Учитывая более строгие европейские стандарты предельного содержания ртути, к числу видов с повышенным ее содержанием в органах и тканях помимо хищных видов также относится и сиг, представленный малотычинковой формой, характеризующейся преимущественно бентосным типом питания (рис. 1).

У отдельных особей (кумжа, окунь, щука) содержание металла значительно превышали величины ПДК, установленные для РФ (0.5 мкг/г сырого веса) (рис. 2). К числу водоемов с повышенными содержаниями по указанному показателю относятся озера Финляндии: Айттоярви, Кантоярви, Меллаломполо, Суоваселькаярви; Норвегии: Ваггетем, Стуораяври, Скрюккебукта, Макеярви, Вирднеяври, Воуттасъярви, Рундватн; России: Кочеяур, Виртуовошъяур, Имандра, Кахозеро, Круглое, Раякоски.

Помимо гидробионтов, изучение элементного состава донных отложений (ДО) водоемов также позволяет судить о масштабах антропогенной нагрузки на пресноводные экосистемы [1]. Однако в районах функционирования крупных промышленных предприятий горно-металлургического комплекса, накопление ртути в тканях рыб и ДО озер имеет выраженный противоположный характер. Ртуть накапливается в ДО в условиях закисления, органической и микробной загрязненности, повышенной цветности воды. Она способна подвергаться метилированию и переводу в более опасную органическую форму. Именно она интенсивно мигрирует по трофическим цепям водоема, на- 


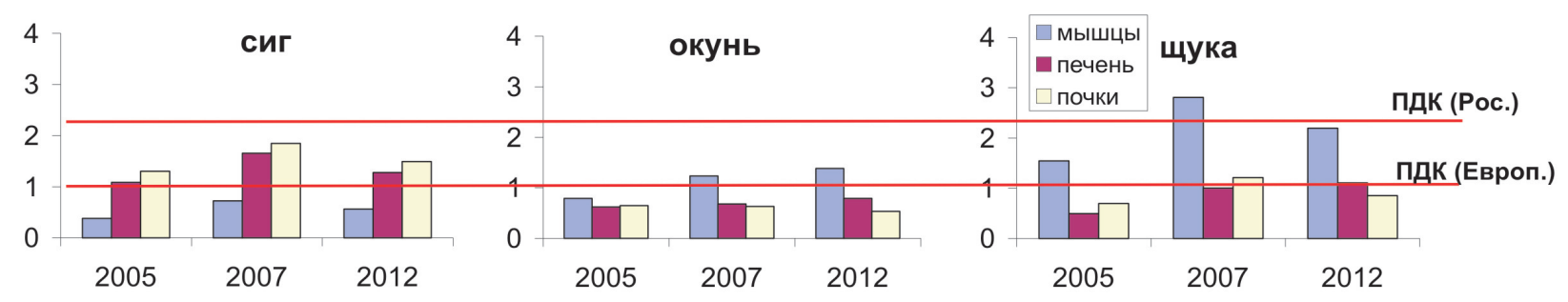

Виртувошъяур
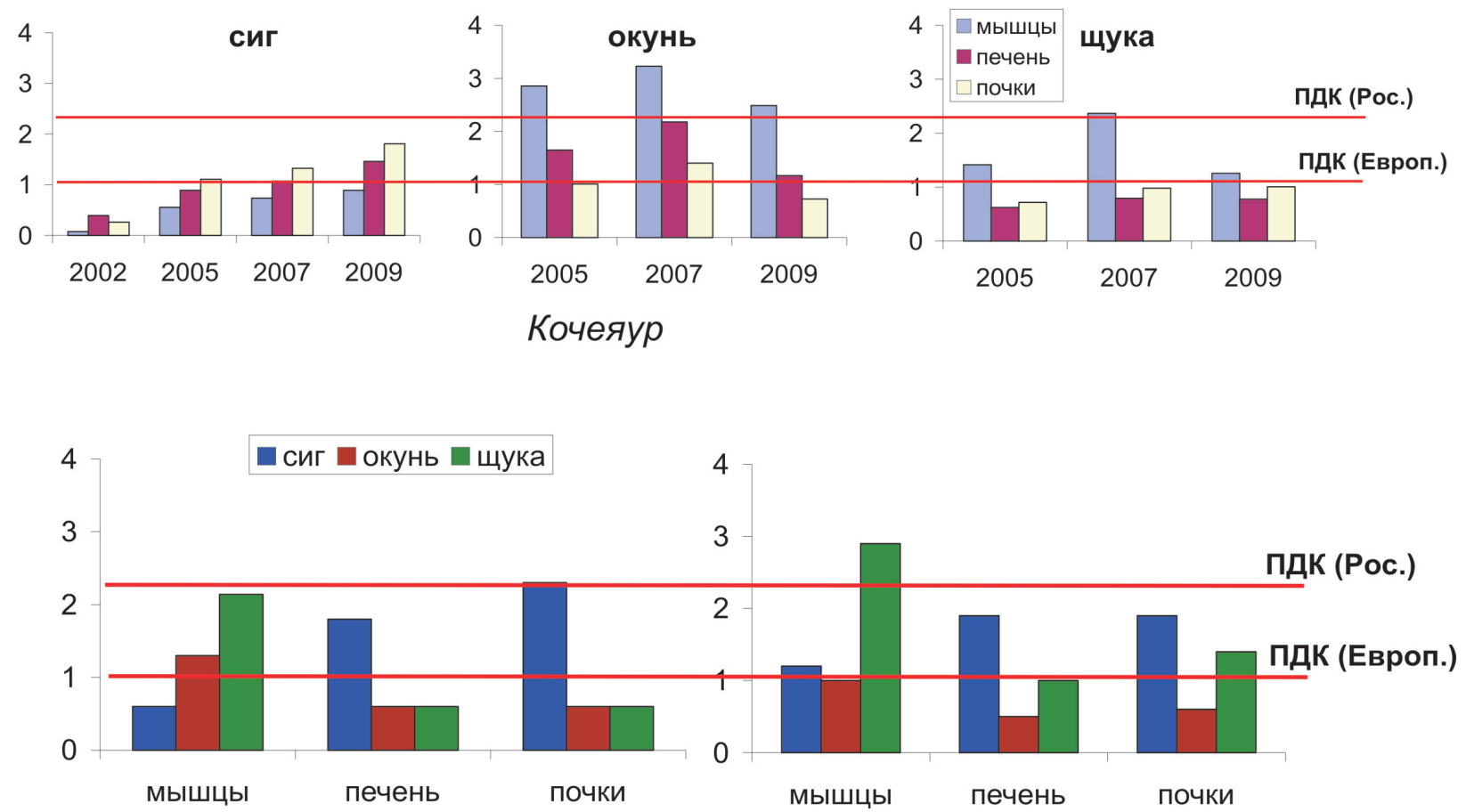

Аиттоярви

Кантоярви

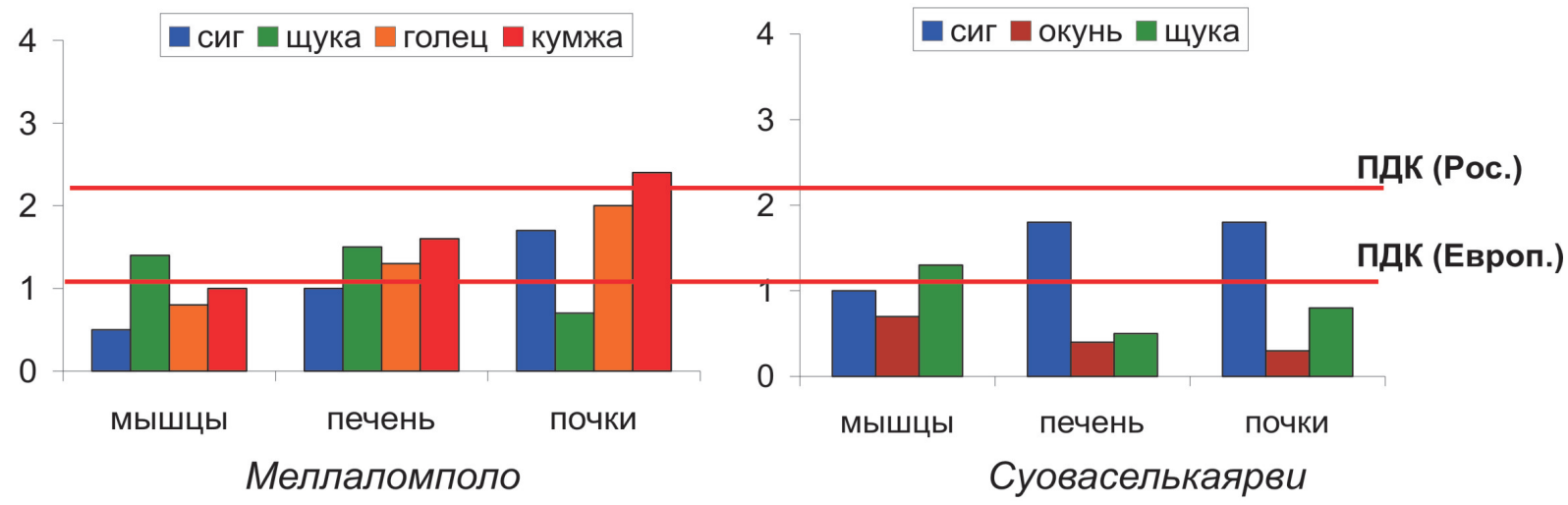

Рис. 1. Долговременные изменения уровней накопления ртути в органах исследованных видов рыб озер России (Виртуовошъяур, Кочеяур) и Финляндии (Аиттоярви, Кантоярви, Меллаломполо, Суоваселькаярви) (в мкг/г сухого веса).

капливаясь в максимальных концентрациях в организмах рыб [10]. Отмечаемые на первый взгляд несоответствия в содержании ртути в донных отложениях озер и тканях рыб в условиях промышленного загрязнения (бассейн р. Паз), могут быть связаны с интенсивной нагрузкой приоритетных тяжелых металлов (прежде всего никеля и меди). В условиях высокой токсичности вод процессы микробиологического метилирования ртути и включение ее в биологический круговорот могут 


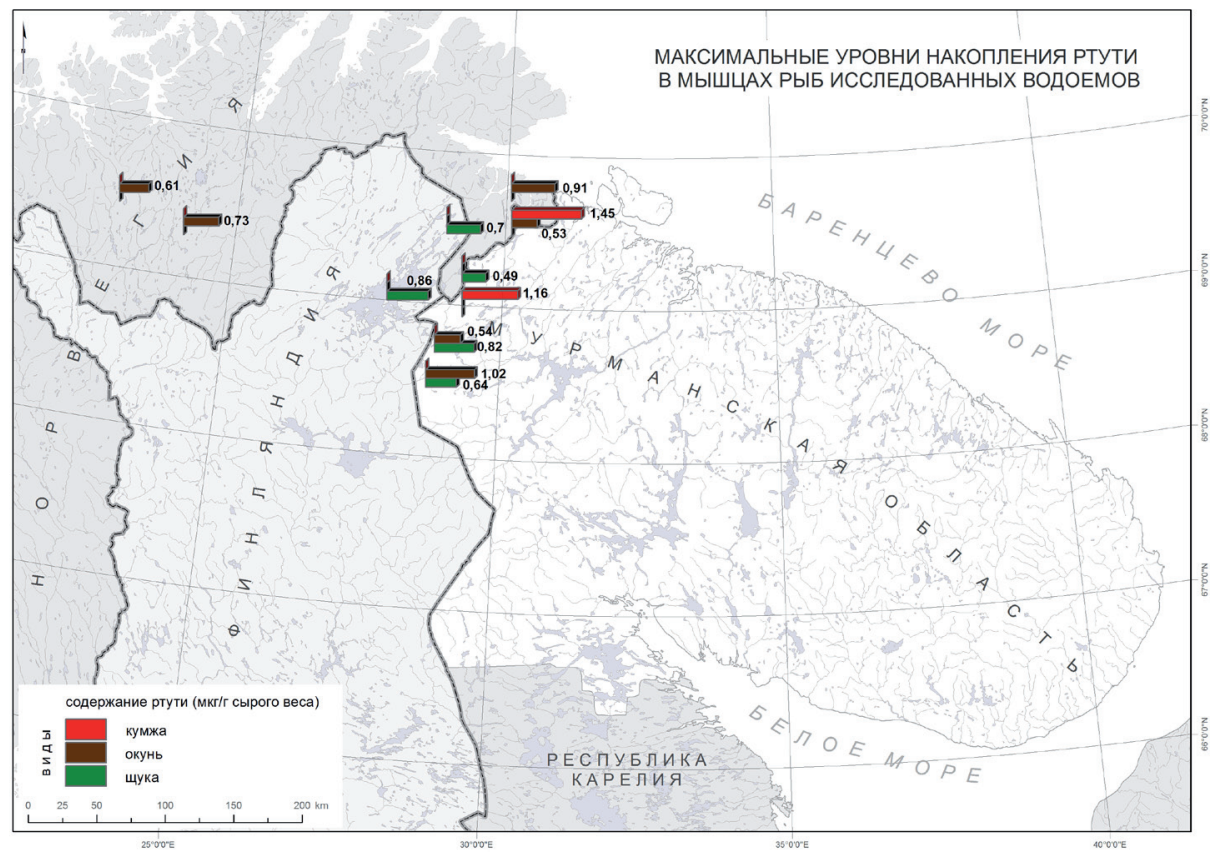

Рис. 2. Максимальные уровни накопления ртути в мышечной ткани рыб озер Мурманской области и приграничного районов Норвегии и Финляндии (в мкг/г сырого веса).

быть сильно снижены, либо практически полностью подавляться. При этом, в седиментах содержание связанной и потенциально опасной ртути может быть велико.

\section{Заключение}

Установлено, что нагрузка на экосистемы озер исследованного района носит крайне неоднородный характер. Полученные результаты показывают, что интенсивность и степень накопления ртути в организмах рыб исследованных водоемов определяется в первую очередь процессами глобального загрязнения атмосферы и в меньшей степени зависят от интенсивности нагрузки на озерные экосистемы локальных источников загрязнения. Значительные величины накопления ртути зарегистрированы практически у всех рассматриваемых видов рыб в водоемах Севера Финляндии, Норвегии и России. Отмечена тесная положительная зависимость накопления ртути от размерновесовых показателей рыб.

На примере водоемов бассейна р. Паз в зоне воздействия предприятия медно-никелевого производства было показано, что закономерности накопления ртути в гидробионтах определяются влиянием приоритетных загрязняющих веществ. Так, в условиях высокой токсичности среды, связанной со значительной нагрузкой никеля, особенности накопления ртути в донных отложениях и тканях рыб носят противоположный характер. Очевидно, это связано с подавлением процессов микробиологического метилирования соединений ртути. Установлено, что накопление ртути в седиментах и организмах рыб исследованных озер имеет тенденцию к росту на протяжении последних десятилетий.

Высокая токсичность ртути и ее производных для арктических пресноводных экосистем требует разработки единой и более жесткой системы нормирования ее содержания в биологических объектах и природных водах России, Норвегии и Финляндии. На основе изучения особенностей накопления ртути в органах и тканях рыб водоемов Северной Фенноскандии предложена система категорий слабого $\left(<0.15\right.$ мкг $/ \Gamma_{\text {сыр. веса }}$ ), умеренного (в диапазоне $0.16-0.20$ мкг $/ \Gamma_{\text {сыр. веса }}$ ), повышенного (в диапазоне 0.21-0.5 мкг/ $\left.\Gamma_{\text {сыр. веса }}\right)$ и высокого $\left(>0.5\right.$ мкг/ $\left.\Gamma_{\text {сыр. веса }}\right)$ загрязнения.

\section{Литература}

1. Даувальтер В.А., Кашулин Н.А. Тяжелые металлы в донных отложениях озер центральной и югозападной частей Мурманской области // Вест. КНЦ РАН. 2016. № 3 (26). С. 79-94. 
2. Комов В.Т., Степанова И.К., Гремячих В.А. Содержание ртути в мыщцах рыб из водоемов СевероЗапада России: Причины интенсивного накопления и оценка негативного эффекта на состояние здоровья людей // Актуальные проблемы водной токсикологии. Борок: ИБВВ РАН. 2004. С. 99-123.

3. Немова Н.Н. Биохимические эффекты накопления ртути у рыбы. М.: Наука. 2005.168c.

4. Akerblom S., Bignert A., Meili M., Sonesten L., Sundbom M. Half a century of changing mercury levels in Swedish freshwater fish // Ambio. 2014. V. 43. P. 91-103.

5. AMAP/UNEP, 2013. Technical Background Report to the Global Atmospheric Mercury Assessment. Arctic Monitoring and Assessment Programme / UNEP Chemicals Branch. 263 pp.

6. Amundsen P-A., Kashulin N.A., Terentjev P.M., Gjelland K., Koroleva I.M, Dauvalter V.A., Sandimirov S.S., Kashulin A.N. and Knudsen R. Heavy metal contents in whitefish (Coregonus lavaretus) along a pollution gradient in a subarctic watercourse // Environmental Monitoring and Assessment. 2011. V 182. P. 301-316.

7. Braaten H.F., Ekerblom S., de Wit H.A., Skotte G., Rask M., Vuorenmaa J., Kahilainen K.K., Malinen T., Rognerud S., Lydersen E., Amundsen P-A., Kashulin N., Kashulina T., Terentyev P., Christensen G., JacksonBlake L., Lund E., Rosseland B.O. ICP Waters report 132/2017 Spatial and temporal trends of mercury in freshwater fish in Fennoscandia (1965-2015). NIVA-Report 7179-2017. Oslo. 72 P. ISBN 978-82-577-6914-7, ISSN 1894-7948.

8. Dastoor, A.P., Larocque Y. Global circulation of atmospheric mercury: a modelling study // Atmospheric Environment. 2004. V. 38. P. 147-161.

9. Dietz R., Sonne C., Basu N., Braune B., O’Hara T., Letcher R.J., Scheuhammer T., Andersen M., Andreasen C., Andriashek D., Asmund G., Aubail A., Baagøe H., Born E.W., Chan H.M., Derocher A.E., Grandjean P., Knott K., Kirkegaard M., Krey A., Lunn N., Messier F., M. Obbard, Olsen M.T., Ostertag S., Peacock E., Renzoni A., Rigét F.F., Skaare J. U., Stern G., Stirling I., Taylor M., Wiig Ø., Wilson S., Aars J. What are the toxicological effects of mercury in Arctic biota? // Science of the Total Environment. 2013. V. 443 (15). P. 775-790.

10. Environmental Science: understanding, protecting, and managing the environment in the Baltic Sea region. Baltic Univer. Press, 2003. 800 p.

11. Kashulin N. A., Terentyev P. M., Amundsen P.-A., Dauvalter V. A., Sandimirov S. S., Kashulin A. N. Specific features of accumulation of $\mathrm{Cu}, \mathrm{Ni}, \mathrm{Zn}, \mathrm{Cd}$, and $\mathrm{Hg}$ in two whitefish Coregonus lavaretus (L.) morphs inhabiting the Inari-Pasvik lacustrine-riverine system // Inland water biology. 2011. V. 4 (3). P. 383-392.

12. Lepom P., Irmer U., Wellmitz J. Mercury levels and trends (1993-2009) in bream (Abramis brama L.) and zebra mussels (Dreissena polymorpha) from German surface waters. Chemosphere. 2012. V. 86. P. $202-211$.

13. Nguetseng R., Fliedner A., Knopf B., Lebreton B., Quack M., Rudel H. Retrospective monitoring of mercury in fish from selected European freshwater and estuary sites // Chemosphere. 2015. V. 134. P. 427-434.

14. Pacyna, J.M., Pacyna E.G., Steenhuisen F., Wilson S. Mapping 1995 global anthropogenic emissions of mercury. Atmospheric Environment, 37-S. 2003. P. 109-117.

15. WHO. Environmental Health Criteria. Methylmercury. 1990. V. 101. Geneva, Switzerland. 